Provided by the author(s) and University of Galway in accordance with publisher policies. Please cite the published version when available.

\begin{tabular}{|c|l|}
\hline Title & $\begin{array}{l}\text { Beyond Budgeting: A Performance Management Model for } \\
\text { Software Development Teams }\end{array}$ \\
\hline Author(s) & Lohan, Garry; Conboy, Kieran; Lang, Michael \\
\hline $\begin{array}{c}\text { Publication } \\
\text { Date }\end{array}$ & 2010 \\
\hline $\begin{array}{c}\text { Publication } \\
\text { Information }\end{array}$ & $\begin{array}{l}\text { Lohan, G., Conboy, K. \& Lang, M. (2010)"Beyond Budgeting: } \\
\text { Teams" in: proceedings of the LESS conference 2010 } \\
\text { (accepted, to appear) }\end{array}$ \\
\hline & \\
Item record & http://hdl.handle.net/10379/1471 \\
\hline
\end{tabular}

Downloaded 2023-04-26T15:11:03Z

Some rights reserved. For more information, please see the item record link above.

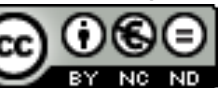




\title{
Beyond Budgeting: A Performance Management Model for Software Devel- opment Teams
}

\author{
Garry Lohan, Kieran Conboy, Michael Lang \\ National University of Ireland, Galway \\ \{Garry.Lohan, Kieran.Conboy, Michael.Lang \}@nuigalway.ie
}

\begin{abstract}
The Beyond Budgeting performance management model enables companies to keep pace with changing environments, to quickly create and adapt strategy and to empower people throughout the organisation to make effective choices. We argue that this performance management model may be ideal for agile software development. Although drawn from different disciplines, both are designed for a customer-orientated, fast-changing operating environment and the Beyond Budgeting model suggests a useful overall framework for research in the performance management of agile software development teams. This paper uses the model as a lens to examine the performance management of agile software development teams within a large multinational. The findings show that some traditional performance management processes (most notably the budgeting process), which were designed to aid in the performance management of software development teams may impede the performance of agile teams due to their suitability adherence to the requirements of the systems development lifecycle model.
\end{abstract}

Key words: Beyond Budgeting; Agile Methods; Organizational Agility

\section{Introduction}

Continued uncertainty and rapid changes to business and technology environments have meant that a software development team's ability to respond to changing user or customer requirements has become increasingly critical. As a means to respond to these changes the software development community has moved from a traditional, plan-driven, structured approach to more agile development methods, which has had a huge impact on the way software is developed worldwide [1-3].

These newer methods of producing software are not always compatible with traditional performance management models (PMMs) [4-6]. As agile methods grow in popularity, it is important that the management control in the organization be set up to complement an agile way of working. An innovation from the accounting literature called "Beyond Budgeting" has shown great promise as a performance management model for a changing business and operating environment $[5,7-12]$. This model is conceptually similar and appears to align well with agile 
methods $[5,11,13,14]$. The research objective of this paper is to examine how the Beyond Budgeting model is being applied in the field of agile software development.

The paper is structured as follows: The next section explores current thinking on performance management and performance management models and introduces the Beyond Budgeting model; the research methodology is then outlined; and the fourth section highlights the major findings of this research, followed by a discussion and conclusion outlining the importance to research and industry.

\section{Performance Management and the Beyond Budgeting Framework}

Performance management models are complex and intertwined, but research tends to ignore the interdependencies between controlling mechanisms and concentrate on simplified and partial areas of the overall PMM. The literature in the area of PMM and management control systems (MCS) increasingly recognizes the need for research to be based on more coherent theoretical foundations [12, 1517]. The tendency to focus only on specific aspects of control systems, as opposed to a more comprehensive and integrated approach, has led to some spurious findings, ambiguity and a potential for conflicting results [15]. There have been calls for a more integrated approach which includes the interdependency between different control mechanisms operating at the same time in the same organisation [18].

Ferreira and Otley [12] and Broadbent and Laughlin [17] have worked on conceptualizing performance management and distinguishing it from performance measurement. They have developed research frameworks that are especially useful when researchers seek to gain an insight into the types of performance management techniques being utilized by organizations. These frameworks are generic in their construction and encompass the whole spectrum of operating environments, from command and control to a more decentralized environment. While the Beyond Budgeting model could be classified within either of the aforementioned frameworks, it is specifically designed for a turbulent, changing business environment. This makes it a suitable PMM for agile software development and means it can be viewed as a standalone framework for research in the field of performance management.

In recent years there has been a move from the bureaucratic, hierarchical organization, -considered ineffective in the context of increased competition brought about by globalization, deregulation, the emergence of powerful developing economies, and development in information technologies, -towards flatter, leaner and more responsive structures [19]. Many authors have raised questions about the efficacy of existing systems of management and government, which first came to prominence during the industrial era, calling now for new models in the context of 
the modern knowledge economy e.g. [20, 21]. Others have questioned the budgeting process and its value in the post-industrial era [5, 22-27].

The Beyond Budgeting performance management model was formally introduced in 2003 as an alternative to the traditional command and control type performance management models, which were usually based on budgetary control mechanisms. Beyond Budgeting is more orientated towards fast changing operational environments and utilizes a sense and respond type of control mechanism, which allows an organisation to keep pace with fast changing environments [10, 28-32]. The emergence of this new concept coincided with the emergence of agile methods and both concepts share many similarities with both having a distinctly agile or adaptive perspective $[5,11,13,14]$. The model consists of six leadership principles and six process principles when taken together and used in an holistic manner help improve performance management within an organization $[5,10]$. Figure 1 lists the twelve principles are they are outlined in the Beyond Budgeting Round Table (www.BBRT.org).

\begin{tabular}{|l|l|}
\hline Leadership Principles & Process Principles \\
\hline $\begin{array}{l}\text { Customers: Focus everyone on im- } \\
\text { proving customer outcomes, not on hi- } \\
\text { erarchical relationships. }\end{array}$ & $\begin{array}{l}\text { Goals: Set relative goals for continu- } \\
\text { ous improvement; do not negotiate } \\
\text { fixed performance contracts. }\end{array}$ \\
\hline $\begin{array}{l}\text { Organization: Organize as a network } \\
\text { of lean, accountable teams, not around } \\
\text { centralized functions. }\end{array}$ & $\begin{array}{l}\text { Rewards: Reward shared success } \\
\text { based on relative performance, } \text { not on } \\
\text { meeting fixed targets. }\end{array}$ \\
\hline $\begin{array}{l}\text { Responsibility: Enable everyone to act } \\
\text { and think like a leader, } \text { not merely fol- } \\
\text { low the plan. }\end{array}$ & $\begin{array}{l}\text { Planning: Make planning a continu- } \\
\text { ous and inclusive process, } \text { not a top } \\
\text { down annual event. }\end{array}$ \\
\hline $\begin{array}{l}\text { Autonomy: Give teams the freedom } \\
\text { and capability to act; do not micro- } \\
\text { manage them. }\end{array}$ & $\begin{array}{l}\text { Controls: Base controls on relative } \\
\text { indicators and trends, } \text { not variances } \\
\text { against a plan. }\end{array}$ \\
\hline $\begin{array}{l}\text { Values: Govern through a few clear } \\
\text { values, goals and boundaries, } \text { not de- } \\
\text { tailed rules and budgets. }\end{array}$ & $\begin{array}{l}\text { Resources: Make resources available } \\
\text { as needed, not through annual budget } \\
\text { allocations. }\end{array}$ \\
\hline $\begin{array}{l}\text { Transparency: Promote open infor- } \\
\text { mation for self-management; do not } \\
\text { restrict it hierarchically. }\end{array}$ & $\begin{array}{l}\text { Coordination: Coordinate interactions } \\
\text { dynamically, } \text { not through annual plan- } \\
\text { ning cycles. }\end{array}$ \\
\hline
\end{tabular}

Figure 1. The Beyond Budgeting Performance Management Model 


\section{Research Methodology}

\subsection{Site Selection}

SCC is a large multinational oil and gas firm with an internal information systems division that builds customized software solutions, mainly for internal clients. The organization started moving from a traditional command and control model during the 1990s and in 2005 began the process of implementing the Beyond Budgeting model. As one of the earliest adopters of the Beyond Budgeting model and an early adopter of the Scrum methodology, the organization presented an excellent opportunity to gain an insight into how the Beyond Budgeting model is being operationalized.

The development teams within the organization had traditionally worked with waterfall development and the transition to agile development processes raised questions on the suitability of the surrounding supporting processes. Organizational structures, which had supported the use of the waterfall method, meant that the emphasis on traditional project management practices needed to be changed to support the more agile way of developing solutions. In many cases, the end user was not the direct customer of the development team. The teams studied were often part of a larger umbrella group and therefore their customers were more often than not an internal downstream function of the organization.

\subsection{Data Sources and Analysis}

A literature review of each principle from the Beyond Budgeting framework formed the basis of an interview protocol used in this study [33]. Data were collected through a variety of methods: unstructured and semi-structured interviewing, informal meetings and follow up communication via email and commentary of findings. The study was conducted within the IS division of SCC which builds customized software solutions for internal and external clients. Ten formal interviews were carried out with personnel from four different Scrum projects and in three different locations. Four of those interviewed were external consultants hired to become part of a Scrum team once the project had kicked off. The other six interviewees spoke as Scrum masters although some were previously project managers whose role had been redefined to suit the Scrum methodology. Several of these were Scrum masters who were responsible for a large number of teams.

All transcripts were recorded and transcribed entirely. The transcriptions were imported into NVivo for coding. Reflexive remarks and memos made during both the interview stage and the analysis stage helped to interpret the data and lead to the identification of emergent themes. Precautions were taken to corroborate the interpretations made $[34,35]$. Responses were checked for representativeness by examining them across participants. For example, team members' reports of their experience with their customers were checked against the reports from other team members and the Scrum masters. The participants in the study also provided commentary, correction and elaboration on drafts of the findings and framework. 


\section{Findings}

The Beyond Budgeting model is an holistic management model suited to an agile environment. A previous literature review discussed each principle of the model and how they may be operationalized in the context of agile software development [33]. This section focuses on the results of this case study that examined how each principle was or was not being operationalized in a real world setting. What is working well and what is not working well is examined under each principle of the Beyond Budgeting model.

\subsection{Customer Focus}

Where project teams were involved in larger umbrella programs, a Scrum of Scrums took place on a regular basis. This helped disseminate customer knowledge information. There are no specific knowledge repositories utilized to store customer knowledge gathered over time (which could be used by other teams working with the same customer at a later date) and inter team knowledge sharing needed improvement. Filtering of customer requirements through customer proxies or product owners was a cause for concern for some team members. In some cases, team members were encouraged to get requirements from the product owner and not individuals they might know from the customer side. One Scrum master gave the reason for this: "These are individuals, they do not represent the business need, the product owner represents the business need. So it's really about channelling this into one person who is there to ensure that this is what the business needs and it's not the preference of one aspect of the business."

Getting and using feedback at the end of each sprint was standard across all teams. However the level of customer or in many cases, proxy customer involvement was very hit and miss with some teams having a great customer relationship and other getting minimal input from their customers. As one Scrum master put it: "It's the first time I've seen such a close relationship [with the customer]. You could say that we've been lucky to have this group as an internal customer, of course they are more motivated to get Scrum up and working and we have a lot of commitment, but its not a default that everyone is as committed"

Another Scrum master agrees that the organization is committed to providing good quality service and say that the reason for implementing Scrum was because: "We wanted to be more customer focused and deliver business value faster"

\subsection{Organization}

While there were operating guidelines within which the team was expected to operate, the team members had quite a lot of freedom to make decisions and try out new ideas that could improve the performance of the team. The following quote from one team member illustrate this: "Yeah, the team is pretty much allowed to do whatever we feel would improve the quality of the code, the quality of 
the process, increase the efficiency, as long as we are able to justify why we would like to spend 5 or 10 hours on an activity, that is usually fine."

Members were consulted regarding decisions made on new team members or training requirements but they would not necessarily have much control over the final decision. Operating guidelines and decisions such as using the Scrum methodology were, as one team member stated: "mandated from further up the food chain". Larger decisions regarding major project milestones, resourcing, methodologies and project roadmaps were made during the project initiation period when the major stakeholders got together and formulated a high-level project plan.

\subsection{Responsibility}

The onus on coaching team members and enabling members to think and act like leaders lies mainly with the team itself and the Scrum master. While SCC is striving to fully embrace the Scrum concept and develop long lasting teams who share responsibility, this is not yet happening. One reason for this could be that most of SCCs projects involve hiring consultants for the duration of the project or product lifecycle. One Scrum master tells of how the organisation is trying to develop a sense of shared responsibility: "We are working hard on this... ... We are developing the Scrum teams to take more responsibility. But again when you are talking about Scrum teams which are more or less staffed by consultants, they don't have the same kind of responsibility, they are very responsible people but they are doing it according to a contract"

The main obstacle to long lasting teams appears to be the budgeting process. As one Scrum master states: "Sometimes you get a budget that is: you need to run this for 13 months and that ends on Dec 1. But then along the way somebody says, ah but we should get another phase on it but we can't get a budget for it so we will start on Feb 1. Then you get a gap, what do you do in the meantime? We have a really good team, should we just dismantle it and try to assemble it in 2 months?"

Many of the team members are hired as consultants for a specific project. Highlevel project goals are already in place and the team's priority is to achieve those goals. The use of short-term contracts may hinder the development of long lasting, high performing teams. One Scrum master highlights the problem with yearly budgets and why it is reasonable to assume there may be some myopic thinking among team members: "We only have a short horizon here; we only have a budget for the rest of the year which means we can't think any longer. That, at least, is what we are being told, even though we know a lot of the task will probably go on the next year"

\subsection{Autonomy}

Generally, team members felt they had a lot of autonomy when it came to their daily work. Members participated in daily stand-ups, iteration meetings, retrospectives and show-and-tell sessions and felt that their input was listened to and valued. While team members felt they had a certain amount of autonomy or were 
empowered to carry out their daily tasks, Scrum masters were somewhat more sceptical with one Scrum master wondering about the organisations support for Scrum: "So how do we get the whole organization to support it, how do we define roles and responsibilities in our government structure that actually fits the ambition of delegating responsibility further down in the organization"

Autonomy is also about team members feeling that their input and work is valued by the organization. On one project, it was the confidence in the product owner that left team members unsure of the value of their work. They felt that the product owner filtered requirements and suggestions and the value they contributed was diluted because of this. One team member had this to say: "The product owner filters the users in such a way that I feel we don't get the requirements which could be beneficial to the users to actually have implemented",

Confidence in the product owner was sometimes not very high but generally, team members felt that they were carrying out important work and that this work was valued. A Scrum master explains the probable reason for this: "The product owner has made some effort in creating a vision, so I think they [the team] are not only making bricks, I think they know what kind of cathedral they are going to build"

\subsection{Values}

Generally, the teams work within a set of operating guidelines that are usually decided during the project initiation. A technological roadmap is set out at the beginning of the project that outlines the goals and major milestones of the project. One Scrum master describes the process: "Many of the participants in the Scrum teams are actually developing the target and the mission together with the product owners, so they are actually involved in developing it but decisions are not taken by the Scrum teams, they are taken by the product owner and asset owner, but its mostly based on recommendations and input from the teams"

This roadmap is communicated clearly to the teams and they have an opportunity to make further suggestions or recommendations. This is essentially, what the Beyond Budgeting principle is recommending. However, while detailed rules are not used for governing, yearly budgets still play and important role and have a big affect on the behaviours of the teams.

\subsection{Transparency}

There was a consensus within all the interviewees that they had all relevant information they required for their daily operations. The organization has formal mechanisms in place, such as coordination workshops and demo sessions, to help promote a wider understanding and transparency among teams, but as one Scrum master says: "Our intention is good, we would like to think in an holistic perspective and think integration and ensure everyone has the same understanding and so on, but the amount of work makes us focus on what is closest to us and that is the 
small group of people we are working with and that also goes for the Scrum teams",

The teams all appear to be happy with the Scrum methodology and the transparency it offers through either the project management tool or charts on wall spaces used by some teams. A Scrum master tells how transparency is complemented and teams are getting up to date information: "We are sending out newsletters to the project team where we inform them about what has been reported to the steering committee, regarding whether we are within or beyond target and what kind of actions have been agreed to get us on target with time or whatever. They know about some of the largest risks we have and any mitigating actions and so on. So they have a good feeling on how the project is performing",

\subsection{Goals}

The goal setting process for team members is an informal process within SCC. Many team members are hired as consultants for specific projects and come into the team with a specifically requested skill set. The move to agile has seen Scrum masters and project manager's focus more on behavioural skills as one Scrum master makes clear: "When I select team members the next time I will be much more focused on how they actually behave inside the team and to have really clever people is not that important"

Project roadmaps are already in place when a team is assembled and project milestones outlined. The team members see these as their main goals and within those boundaries they decide, as a team, along with the product owner their shorter-term goals. Within the project duration, most team members felt that their Scrum master would informally speak with them regarding their short-term individual goals. Some senior stakeholders may have their own personal goals but generally, the team is viewed as having a team goal. A Scrum master explains: "The goals are the Key Performance Indicators (KPIs). Every single department has their own KPIs, process owners have them, line managers, asset owners, everybody has them, and on project as such, we are measured on timely delivery and quality and all that. It does not go down to every single individual on the project. I would say it is fairly informal how this happens in a Scrum project when it comes to each individual"

\subsection{Rewards}

Group rewards schemes are not carried out within SCC. All those interviewed seemed to appreciate being part of a team working towards specific goals, i.e. project milestones, go-live dates etc. Groups were rewarded to some extent' for example one Scrum master says: "The team gets the applause definitely from the customers and those who lead the project when everything goes well"

The person to whom the team member is reporting carries out individual reviews. This person is expected to give an objective insight into the performance of the team member. As the team members are consultants with different companies, 
their individual reward packages were different and were not discussed during these interviews. In many respects, the reward system is in line with the Beyond Budgeting principle, because although the team targets project milestones, these targets are set only by time and there is room for de-scoping if required. Team members are reviewed based on relative performance and both technical and behavioural factors are considered. The review is not carried out by peers as recommended by Beyond Budgeting and is therefore open to the subjective opinion of the reviewer (generally the Scrum master).

\subsection{Planning}

Once a project roadmap is decided upon and project milestones or decision gates are set then the team has considerable flexibility to change interim plans. The ability to re-prioritize the functionality being delivered is one of the main differences between a Scrum project and a traditional waterfall project. A Scrum master explains the planning process: "It's the product owner, who at all times defines what is in the scope, so the only thing we can promise is that we can start the project at one time and stop it at another time. If we are keeping to that time schedule then we can deliver within this cost estimate but whatever you get for that money within that timeframe is basically up to the product owners and asset owners to prioritize [with input from the team]."

Again, working with the Scrum methodology means the teams planning process is both inclusive and flexible. The following quote from a team member illustrates this point: "That's why we are running Scrum, because we can adjust moving forward, instead of working for a year and going to the customer and saying this is what we have delivered and they say that's not what we asked for. That's what I like about Scrum"

\subsection{Control}

Once the budget has been established for a project then, that is deemed as the boundary condition. For team members the key performance indicators are to meet the project milestones that indicate that the project is running within budget. All projects require a high level of quality and de-scoping of functionality may happen in order to meet milestones within budget. One Scrum master explains how their team stays within the budget boundaries: "We have been able to hold cost exactly at budget and quality we uphold by taking out of the box as much as possible"

Although not linked to the project timeline, it may be worth noting, that in order to comply with IT SOX requirements the project management office requires an information risk assessment to be carried out after each sprint. This is linked to key controls for confidentiality, reliability and integrity of the information and is done by asking some key questions each month when solutions are put into production. 


\subsection{Resources}

The budget for projects is fixed and when new resources are needed then the Scrum master will decide with other stakeholders what to prioritize. Functionality may be reduced or team members may be removed from the team to keep within the budget. There are mechanisms through which additional resources can be acquired which were not within the original budget a particular team.

The current process within SCC means that high performing teams may lose team members during the duration of a project in order to keep within the budget. This is not in line with the objective of having long lasting teams. One Scrum master shows how the fixed budget has a negative impact on performance: "They were good [the team], they were doing so well and they were delivering excellent IT products, but they knew they were coming to an end, that was a challenge. They were probably at their peak... ....We really saw how good a team can be if they're allowed to stay in the same team for almost 2 years, they were doing so well"

\subsection{Coordination}

The organization has mechanisms in place such as intranets, video conferencing facilities, knowledge wikis, etc. designed to encourage continuous interaction. Workloads often mean that teams only interact with those they are involved with in their daily tasks. Scrum of Scrums are used to improve inter team communication. One Scrum master gives his view: "I still think there is quite a lot that could be benefited for better coordination between team at a team level and perhaps more importantly some improved communication between the product owners"

There was a consensus that communication and coordination could be improved but the organization does appear to be trying to develop a good communication environment especially when teams are co-located. Some found informal outings very beneficial with one team member noting: "When it's informal then it's easier to get to know people and then it's much easier to go and ask for help next time".

\section{Discussion}

Although the Beyond Budgeting model is designed as an holistic performance management model with each principle interacting with, and supporting the other principles, implementing it as such, is not always feasible. It is clear that SCC has a motivated and enthusiastic IS department who are fully embracing the Scrum concept. Team members are generally happy with the Scrum environment and the support they receive. More experienced Scrum masters or former project managers have some issues regarding the support for the concept of agility coming from areas such as project management and line management. Many feel that these areas are improving and need to continue to improve to create a truly agile environment. One senior Scrum master states that they have seen what he calls "organizational transition lock" when it comes to defining roles and responsibilities in the 
organizations government structure that actually fit the ambition of delegating responsibilities further down the organization and having self-managing teams. There is a sense that the Scrum methodology could be turned into just another methodology that feeds into the traditional project management structure of fixed budgets and quarterly reporting.

The project budget is still the dominant factor affecting team performance management in SCC. There is considerable flexibility in the project scope but the budget is still the bottom line. Teams that are performing well generally disband at the end of a project lifecycle even though they may be performing well. The main influencing factors appear to be the project budget and the way the project management is structured. In order to create long lasting teams it may be better to focus more on the product and have teams working on a product rather that on a project-by-project basis. More of a focus on the product, rather than a number of individual projects to be staffed and resourced individually, may allow for the creation of longer lasting teams.

The use of consultants gives SCC considerable flexibility to create and disband teams when a project begins or ends. This has the negative affect of inducing myopic thinking among team members who are working on a contract-by-contract basis. Another issue here is the length of time it takes to get a team working well together within the Scrum methodology. One Scrum master estimated that it took 12 weeks $(3 * 4$ week sprints) to get a team working well together. Creating and disbanding teams according to the budget or project timeline creates problems for the Scrum masters who are often the interface between the Scrum team and other functions outside the team, such as the staffing department (line management), the project management office and the business units. Core teams with expertise in many areas, which may be expanded by consultants as required, may be the way forward. If these teams were to become long lasting teams focused on products rather than single projects at a time, then SCC can move easily onto the next step of its implementation of the Beyond Budgeting model.

\section{Conclusion}

The Beyond Budgeting model was first introduced in 2003 as a management model, which empowers employees with the responsibilities, authority, and support they need to create value for the organisation, with the minimum amount of control required to ensure they are operating within organizational boundaries. This case study develops the model and adapts it for use within the context of Scrum teams operating in a large organization. We contend that it is the optimum management model for a Scrum team and examined how it is being applied in practice, what is working and what needs improvement. The implications for theory and practice are discussed below. 


\subsection{Implication for Theory}

As an holistic performance management model, the Beyond Budgeting model covers the entire spectrum of performance management. Many different theoretical bases are utilised, e.g. customer focus, decentralization, autonomy, governance, goal setting, relative performance evaluation, group rewards, control theory, dynamic resources, etc., all of which can be considered under the broad umbrella of performance management. Further research can establish which aspects of the model will work and in what context. For example, will the model function effectively if group reward schemes are or are not in place or if peer reviews do or do not take place? Are there cultural issues to be considered which will determine the effectiveness of the model? This paper outlines how the Beyond Budgeting model can be used to examine the performance management techniques of Scrum teams and how these techniques are assisting or impeding the effectiveness of the teams.

\subsection{Implications for Practice}

The Scrum methodology is fundamentally similar to the Beyond Budgeting model. This paper highlights the issues Scrum teams have when it comes to operating efficiently in an environment where supporting processes are not always complementary to a Scrum way of working. By examining each principle separately and highlighting how it is currently being applied within SCC, we show a way forward in the design of performance management systems which are particularly suited to an agile way of working. We believe that all the principles of the Beyond Budgeting model complement the Scrum methodology and for organisations who wish to use Scrum then the Beyond Budgeting model represents a suitable and complementary performance management model.

\section{References}

1. Conboy, K., Agility from First Principles: Reconstructing the Concept of Agility in Information Systems Development. Information Systems Research, 2009. 20(3).

2. Conboy, K. and B. Fitzgerald, Toward a conceptual framework of agile methods. Extreme Programming and Agile Methods - Xp/ Agile Universe 2004, Proceedings, 2004. 3134: p. 105-116.

3. Dybå, T. and T. Dingsøyr, Empirical studies of agile software development: A systematic review. Information and Software Technology, 2008. 50(9-10): p. 833-859.

4. Boehm, B. and R. Turner, Management challenges to implementing agile processes in traditional development organizations. Software, IEEE, 2005. 22(5): p. 30-39.

5. Bogsnes, B., Implementing Beyond Budgeting: Unlocking the Performance Potential. 2009, New Jersey: J Wiley \& Sons. 
6. Qumer, A. and B. Henderson-Sellers, A framework to support the evaluation, adoption and improvement of agile methods in practice. Journal of Systems and Software, 2008. 81(11): p. 1899-1919.

7. Davila, A., G. Foster, and M. Li, Reasons for management control systems adoption: Insights from product development systems choice by early-stage entrepreneurial companies. Accounting, Organizations and Society, 2009. 34(3-4): p. 322-347.

8. Drury, C., Management and Cost Accounting/ London: South-western, 2008. 2008.

9. Hansen, S.C., D.T. Otley, and W.A. Van der Stede, Practice Developments in Budgeting: An Overview and Research Perspective. Journal of Management Accounting Research, 2003. 15: p. 95-116.

10. Hope, J. and R. Fraser, Beyond Budgeting: How Managers can Break Free from the Annual Performance Trap. 2003, Boston, Mass: Harvard Business School Press.

11. Poppendieck, M. and T. Poppendieck, Leading Lean Software Development: Results Are Not the Point. 2010, Upper Saddle River, NJ: AddisonWesley.

12. Ferreira, A. and D. Otley, The Design and Use of Performance Management Systems: An Extended Framework for Analysis. Management Accounting Research, 2009. 20: p. 263-282.

13. Ambler, S.W. Architecture and Design. Dr Dobb's Journal 2008.

14. Highsmith, J. An Adaptive Performance Management System. Cutter Consortium Executive Summary 2006; Available from: http://www.infoq.com/resource/articles/Adaptive-Performance-

Management/en/resources/apms0606.pdf.

15. Chenhall, R.H., Management control systems design within its organizational context: findings from contingency-based research and directions for the future. Accounting, Organizations and Society, 2003. 28(2-3): p. 127-168.

16. Covaleski, M.A., et al., Budgeting Research: Three Theoretical Perspectives and Criteria for Selective Integration. Journal of Management Accounting Research, 2003. 15: p. 3-49.

17. Broadbent, J. and R. Laughlin, Performance Management Systems: A Conceptual Framework. Management Accounting Research, 2009. 20: p. 283-295.

18. Abernethy, M.A. and P. Brownell, Management control systems in research and development organizations: The role of accounting, behavior and personnel controls. Accounting, Organizations and Society, 1997. 22(3-4): p. 233-248.

19. Berry, A.J., et al., Emerging themes in management control: A review of recent literature. The British Accounting Review, 2009. 41(1): p. 2-20.

20. McFarland, K.R., Should You Build Strategy Like You Build Software? MIT Sloan Management Review, 2008. 49(3): p. 69-74. 
21. Manville, B. and J. Ober, A Company of Citizens. 2003, Boston, MA: Harvard Business School.

22. Schmidt, J.A., IS IT TIME TO REPLACE TRADITIONAL BUDGETING? Journal of Accountancy, 1992. 174(4): p. 103-107.

23. Dugdale, D. and S. Lyne, Budgeting. Financial Management (14719185), 2006: p. 32-35.

24. Howell, R.A., Turn Your Budgeting Process Upside Down. Harvard Business Review, 2004. 82(7/8): p. 21-22.

25. Cassell, M., Budgeting and more. Management Accounting: Magazine for Chartered Management Accountants, 1999. 77(8): p. 22.

26. Kennedy, A. and D. Dugdale, Getting the most from BUDGETING. Management Accounting: Magazine for Chartered Management Accountants, 1999. 77(2): p. 22.

27. O'Brien, R., Living with budgeting. Management Accounting: Magazine for Chartered Management Accountants, 1999. 77(8): p. 22.

28. Fraser, R., Figures of hate. Financial Management (14719185), 2001: p. 22.

29. Hope, J. and R. Fraser, Take it Away. Accountancy, 1999. 123(1269): p. 50-51.

30. Hope, J. and R. Fraser, New ways of setting rewards: The beyond budgeting model. California Management Review, 2003a. 45(4): p. 104-119.

31. Hope, J. and R. Fraser, Who needs budgets? Harvard Business Review, 2003b. 81(2): p. 108-+.

32. Hope, J. and R. Fraser, Who needs budgets? Response. Harvard Business Review, 2003c. 81(6): p. 132-132.

33. Lohan, G., K. Conboy, and M. Lang, Beyond Budgeting and agile software development: A conceptual framework for the performance management of agile software development teams, in International Journal of Information Systems (under review). 2010: St Louis.

34. Miles, M. and A. Huberman, Qualitative Data Analysis. 1999, London: Sage.

35. Yin, K., Robert., Case Study Research: Design and Methods: Sage, Thousand Oaks, California, 2003. 2003. 